\title{
Dickkopf-1: A Promising Target for Cancer Immunotherapy
}

\author{
Hang Yin Chu ${ }^{1,2}$, Zihao Chen ${ }^{2,3}$, Luyao Wang ${ }^{1,2}$, Zong-Kang Zhang ${ }^{2,3}$, Xinhuan Tan ${ }^{4}$, \\ Shuangshuang Liu ${ }^{4}$, Bao-Ting Zhang ${ }^{2,3}$, Aiping Lu ${ }^{1,2}$, Yuanyuan Yu ${ }^{1,2 *}$ and Ge Zhang ${ }^{1,2 *}$ \\ ${ }^{1}$ Law Sau Fai Institute for Advancing Translational Medicine in Bone \& Joint Diseases, School of Chinese Medicine, \\ Hong Kong Baptist University, Hong Kong, China, ${ }^{2}$ Guangdong-Hong Kong-Macao Greater Bay Area International Research \\ Platform for Aptamer-based Translational Medicine and Drug Discovery, Hong Kong, China, ${ }^{3}$ School of Chinese Medicine, \\ The Chinese University of Hong Kong, Hong Kong, China, ${ }^{4}$ Department of Microsurgery (II), Wendeng Hospital of Traditional \\ Chinese Orthopedics and Traumatology of Shandong Province, Wendeng, China
}

Clinical studies in a range of cancers have detected elevated levels of the Wnt antagonist Dickkopf-1 (DKK1) in the serum or tumors of patients, and this was frequently associated with a poor prognosis. Our analysis of DKK1 gene profile using data from TCGA also proves the high expression of DKK1 in 14 types of cancers. Numerous preclinical studies have demonstrated the cancer-promoting effects of DKK1 in both in vitro cell models and in vivo animal models. Furthermore, DKK1 showed the ability to modulate immune cell activities as well as the immunosuppressive cancer microenvironment. Expression level of DKK1 is positively correlated with infiltrating levels of myeloid-derived suppressor cells (MDSCs) in 20 types of cancers, while negatively associated with $C D 8^{+} T$ cells in 4 of these 20 cancer types. Emerging experimental evidence indicates that DKK1 has been involved in $\mathrm{T}$ cell differentiation and induction of cancer evasion of immune surveillance by accumulating MDSCs. Consequently, DKK1 has become a promising target for cancer immunotherapy, and the mechanisms of DKK1 affecting cancers and immune cells have received great attention. This review introduces the rapidly growing body of literature revealing the cancer-promoting and immune regulatory activities of DKK1. In addition, this review also predicts that by understanding the interaction between different domains of DKK1 through computational modeling and functional studies, the underlying functional mechanism of DKK1 could be further elucidated, thus facilitating the development of antiDKK1 drugs with more promising efficacy in cancer immunotherapy.

Keywords: DKK1, cancer, Wnt signaling pathway, immunotherapy, immune surveillance

\section{INTRODUCTION}

\section{Characterization of Dickkopf-1 (DKK1)}

DKK1 is an inhibitor of Wnt signaling pathway. Dysregulation of DKK1 has recently emerged as a potential biomarker of cancer progression and prognosis for several types of malignancies (1). Further research of DKK1 in oncology has garnered a lot of attention. The Dickkopf family (DKKs) are glycoproteins of 255-350 amino acids. The DKKs consist of four members in vertebrates (DKK1, $2,3,4$ ), each containing two conserved cysteine-rich (Cys) domains involved in protein-protein 
interactions, which make the family unique. Apart from these, the family has no sequence similarity (2-4). Among the DKK family members, DKK1 is the best understood. DKK1 is a 266amino acid protein with an approximate molecular mass of 26$\mathrm{kDa}$, and it possesses six secondary structures, which are two alpha helices and four $\beta$-sheets. It has the colipase-like fold in Cterminal Cys domain, which likely allows it to serve as an interactive surface $(2,5)$. DKK1 expression appears to be preferential in some adult tissues including bone, placenta, prostate, spleen, and colon $(2,6,7)$. DKK1 has been shown to play an important role as a Wnt signaling pathway antagonist in several studies. For example, Dkk1 acts as an inducer in embryonic head formation and limb morphogenesis (8). Inhibition of Wnt signaling by Dkk1 promotes heart muscle formation in the anterior lateral mesoderm while repressing erythropoiesis (9). Moreover, since overexpression of DKK1 in osteoblasts causes osteopenia, it is also regarded as a negative regulator of normal bone homeostasis (10).

\section{DKK1 Inhibition in Wnt Signaling Pathways}

DKK1 was originally identified in Xenopus as an inhibitor of $\beta$ catenin-dependent Wnt signaling and later its human homologue was also proved to have the same function $(2,3)$. The mechanism of DKK1 blocking the Wnt signaling pathway is demonstrated by multiple groups. To initiate the $\beta$-catenindependent Wnt signaling, Wnt needs to bind to Frizzled (FZD) Wnt receptors and low-density lipoprotein receptorrelated proteins 5 and 6 (LRP5/6). DKK1, for antagonizing canonical Wnt/ $\beta$-catenin signaling, does not directly interact with Wnt or FZD but forms complexes with LRP6 on the cell surface $(11,12)$. With the role of high affinity antagonistic ligand for LRP6, DKK1 inhibits the interaction of Wnt, FZD and LRP6, finally resulting in $\beta$-catenin degradation and inactivation of $\beta$ catenin/T-cell specific factor (TCF) transcription complex as well as consequent downregulation of a set of downstream genes regulated by $\mathrm{T}$ cell factors $(13,14)$. Remarkably, the $D K K 1$ gene is proven to be one of these downstream genes targeted by TCF, which indicates that DKK1 might have a self-regulatory function when suppressing TCF gene expression through Wnt signaling antagonist, thus forming a novel Wnt signaling inhibition negative feedback loop (15). According to the binding structure of DKK1 and LRP6, DKK1 could induce LRP6 to achieve a compressed conformation so that to preclude LRP6 from binding to the other ligands (16). Due to the inhibitory function of DKK1 in $\beta$-catenin-dependent Wnt signaling, which was a frequently overactivated pathway in cancer, DKK1 was originally characterized as a tumor suppressor $(17,18)$. It was revealed that DKK1 expression was decreased in gastrointestinal tumors and the gene was frequently silenced (19). Additional studies indicated DKK1 could suppress tumor growth and proliferation by inducing apoptosis of cancer cells $(20,21)$. However, since Wnt signaling has been recognized as one of the most significant oncogenic pathways correlated with immune evasion, this controversy is now being gradually overturned (22, 23). More importantly, there is growing evidence that DKK1 plays an essential role in cancer progression. For example, a recent study has demonstrated that DKK1expression helps cancer cells possess stem cell-like properties by preventing activation of $\beta$-catenin, thereby avoiding elimination from natural killer (NK) cells (24).

Despite findings supporting the regulation function of DKK1 in $\beta$-catenin-dependent Wnt signaling, DKK1 exhibited more complex intervention as it has also been linked to the activation of $\beta$-catenin-independent Wnt signaling. In osteosarcoma, the planar cell polarity-like (PCP) Wnt signaling pathway, which consisted of Ras homolog family member A (RhoA), mitogenactivated protein kinase kinase-4 (MKK4) and Jun N-terminal Kinase (JNK), was activated when DKK1 inhibited Wnt signaling, resulting in transcriptional activation of cancer stem cell marker aldehyde-dehydrogenase-1 (ALDH1) and promotion of tumor progression (25). The mechanism of DKK1 activation of $\beta$-catenin-independent Wnt signaling remains unclear, although the common opinion is that DKK1 is capable of inducing signal transmission from the $\beta$-catenin-dependent pathway to $\beta$-catenin-independent pathways. The effect of DKK1 on cell function is therefore hypothesized to include the modulation of both $\beta$-catenin-dependent and independent Wnt pathways, thus further enhancing the difficulty of regulating the Wnt signaling mechanism.

The identification of the novel DKK1 receptor cytoskeletonassociated protein 4 (CKAP4) provides a new perspective other than Wnt signaling pathway. Further characterization indicates that CKAP4 interacted with phosphatidylinositol 3-kinase (PI3K) and DKK1, leads to the activation of Akt signaling and increases the proliferation of the cancer cells $(26,27)$. These data suggest a scenario in which DKK1 can signal through a Wnt receptor-independent pathway to promote tumor growth. More evidence is needed to support this hypothesis.

\section{OVER-EXPRESSION OF DKK1 IN CANCERS}

\section{Clinically Elevated Levels of DKK1 in the Serum and Tissue Samples of Cancer Patients}

In recent clinical studies, dysregulation of the DKK1 was highlighted in various cancers including angiogenesis, metastasis, and other advanced invasion, and this was usually associated with poor prognosis (1). From the meta-analysis evaluating the relationship of DKK1 overexpression and prognosis of patients with gastric cancer, DKK1 was defined to be a prognostic marker with its association to vascular and lymphatic invasion, distant metastasis and low overall survival (28). According to other findings, DKK1 overexpression was also observed in breast cancer, ovarian serous carcinoma, lung and esophageal carcinoma (29-31). More importantly, elevation of both serum DKK1 levels detected by enzyme-linked immunosorbent assay (ELISA) and DKK1 protein levels assessed by immunohistochemistry has been found in different kinds of cancers including breast cancer, pancreatic ductal 
adenocarcinoma, esophageal squamous cell carcinoma, and non-small cell lung cancer, and this was in accordance with the cancer metastases or poor prognosis (31-33). The other studies also indicated the role of DKK1 as a novel serologic and prognostic biomarker due to its increased serum concentrations in various cancers, including gynecological cancer (34), prostate cancer (35), hepatocellular carcinoma (36), bladder cancer (37), lung cancer (38), multiple myeloma (39), and osteosarcoma (40).These data implied that DKK1 could be a novel diagnostic and prognostic biomarker and a promising therapeutic target for many cancers.

\section{Gene Expression Profiles From the Cancer Genome Atlas (TCGA)}

To acquire the latest $D K K 1$ gene expression profiles in a more comprehensive manner, we conducted statistical analysis with samples from TCGA data portal. The level-3 RNA-sequencing expression data (Fragments Per Kilobase Million (FPKM)) was retrieved by 'TCGAbiolinks' $\mathrm{R}$ packages (41). In this study, a total of 9677 tumor samples and 916 normal samples were downloaded. Subsequently, FKPM was transformed to Transcripts Per Kilobase Million (TPM) values using the formula TPMi $=$ FPKMi/sum $\left(\right.$ FPKMj) $\times 10^{6}$. The FKPM value was normalized by $(\log 2+0.1)$. We specifically selected the mean values of normalized DKK1 TPM mRNA to do the Student's $t$ test to verify the differential expression pattern in various tumor types (Table 1 and Figure 1). The results demonstrated that DKK1 mRNA was overexpressed in a wide range of tumors (14 out of 27 types analyzed), such as esophageal, colon, stomach, and uterine corpus endometrial carcinoma, providing diverse research directions about the roles of DKK1 in tumors. Consistent with other bioinformatic analysis, a significant overexpression of DKK1 was revealed in head and neck squamous cell carcinoma (HNSC), pancreatic adenocarcinoma (PAAD), and lung squamous cell carcinoma (LUSC), with DKK1 overexpression being associated with shorter disease-free survival (DFS) (42). These results implied that DKK1 could be an advantageous serologic biomarker indicative of tumorigenesis and poor prognosis.

\section{Correlation Between Expression of DKK1 and $\beta$-catenin in Cancer Tissues}

Along with the high DKK1 level, the $\beta$-catenin accumulation was found to be elevated in tumor tissues by immunohistochemistry (IHC) staining and this was linked to poor clinical outcome, which could be observed in chondrosarcoma, triple-negative breast cancer, hepatocellular carcinoma, and human hilar cholangiocarcinoma (43-46). We calculated the correlation between DKK1 and CTNNB1 (the gene that encodes $\beta$-catenin) by analyzing the mRNA levels in 10593 samples from the TCGA dataset. A positive correlation (correlation value: 0.13 ; $P<$ 0.0001; Pearson's correlation coefficient) was found between the two genes. The coexistence of DKK1 and $\beta$-catenin could be elucidated by a negative feedback mechanism. Since DKK1 has been identified as a target gene of activated $\beta$-catenindependent signaling, the abnormal activation of $\mathrm{Wnt} / \beta$-catenin
TABLE 1 | Differentially expressed analysis of DKK1 between Tumor and Normal samples in Pan-cancer Texts in red indicate carcinomas with significant higher DKK1 expression level compared to normal sample $(P<0.05)$.

\begin{tabular}{|c|c|c|c|c|}
\hline Abbreviation & Name & $\begin{array}{l}\text { Normal } \\
\text { Sample }\end{array}$ & $\begin{array}{l}\text { Tumor } \\
\text { Sample }\end{array}$ & P.Value \\
\hline BLCA & Bladder Carcinoma & 19 & 414 & 0.004 \\
\hline BRCA & Breast Invasive Carcinoma & 120 & 1102 & 0.256 \\
\hline CESC & $\begin{array}{l}\text { Cervical Squamous Cell } \\
\text { Carcinoma and Endocervical } \\
\text { Adenocarcinoma }\end{array}$ & 5 & 304 & 0.159 \\
\hline CHOL & Cholangiocarcinoma & 9 & 36 & 0.001 \\
\hline COAD & Colon Adenocarcinoma & 43 & 478 & 0.001 \\
\hline ESCA & Esophageal Carcinoma & 12 & 161 & 0.009 \\
\hline GBM & Glioblastoma & 18 & 156 & 0.822 \\
\hline HNSC & $\begin{array}{l}\text { Head-Neck Squamous Cell } \\
\text { Carcinoma }\end{array}$ & 46 & 500 & 0.001 \\
\hline KICH & Kidney Chromophobe & 24 & 65 & 0.001 \\
\hline KIRC & $\begin{array}{l}\text { Kidney Renal Clear Cell } \\
\text { Carcinoma }\end{array}$ & 73 & 538 & 0.305 \\
\hline KIRP & $\begin{array}{l}\text { Kidney Renal Papillary Cell } \\
\text { Carcinoma }\end{array}$ & 33 & 288 & 0.247 \\
\hline LGG & Low Grade Glioma & 18 & 511 & 0.309 \\
\hline LIHC & Liver Hepatocellular Carcinoma & 53 & 371 & 0.001 \\
\hline LUAD & Lung Adenocarcinoma & 61 & 533 & 0.273 \\
\hline LUSC & Lung Squamous Cell Carcinoma & 49 & 502 & 0.001 \\
\hline OV & Ovarian Cancer & 5 & 374 & 0.858 \\
\hline PAAD & Pancreatic Adenocarcinoma & 5 & 177 & 0.387 \\
\hline PCPG & $\begin{array}{l}\text { Pheochromocytoma and } \\
\text { Paraganglioma }\end{array}$ & 8 & 178 & 0.635 \\
\hline PRAD & Prostate Adenocarcinoma & 53 & 498 & 0.001 \\
\hline READ & Rectum Adenocarcinoma & 11 & 166 & 0.040 \\
\hline SARC & Sarcoma & 6 & 259 & 0.810 \\
\hline SKCM & Skin Cutaneous Melanoma & 103 & 369 & 0.389 \\
\hline STAD & Stomach Adenocarcinoma & 32 & 375 & 0.001 \\
\hline TGCT & Testicular Germ Cell Tumors & 6 & 150 & 0.001 \\
\hline THCA & Thyroid Carcinoma & 66 & 502 & 0.001 \\
\hline THYM & Thymoma & 2 & 119 & 0.424 \\
\hline UCEC & $\begin{array}{l}\text { Uterine Corpus Endometrial } \\
\text { Carcinoma }\end{array}$ & 36 & 551 & 0.004 \\
\hline
\end{tabular}

induced by mutation of other signaling components may promote $\beta$-catenin accumulation and thus provoke the elevation of DKK1 expression (15). The self-regulatory function of secreted DKK1 blocking its own transcription also supported this statement (47). However, a significant negative correlation was observable between $\beta$-catenin and DKK1 by IHC staining in epidermal neoplasms (48). This inconsistent result can be attributed to the variance in studies' characteristics such as sample size, cancer staging, and location of tumor lesions, while it also suggests that the mechanism of DKK1 affecting cancer cells can be varied depending on cancers. Despite the positive correlation between $D K K 1$ and CTNNB1 mRNA levels and protein levels, positive tissue microarray data of the two proteins did not match completely from hepatocellular carcinomas patients, suggesting that DKK1 expression could be mediated by other molecules, for instance, progesterone and transforming growth factor- $\beta 1$ (TGF $\beta 1)(45,49,50)$. Collectively, DKK1 is a potential predictor for the prognosis of a wide range of human cancers, along with a positive correlation with $\beta$-catenin expression. 


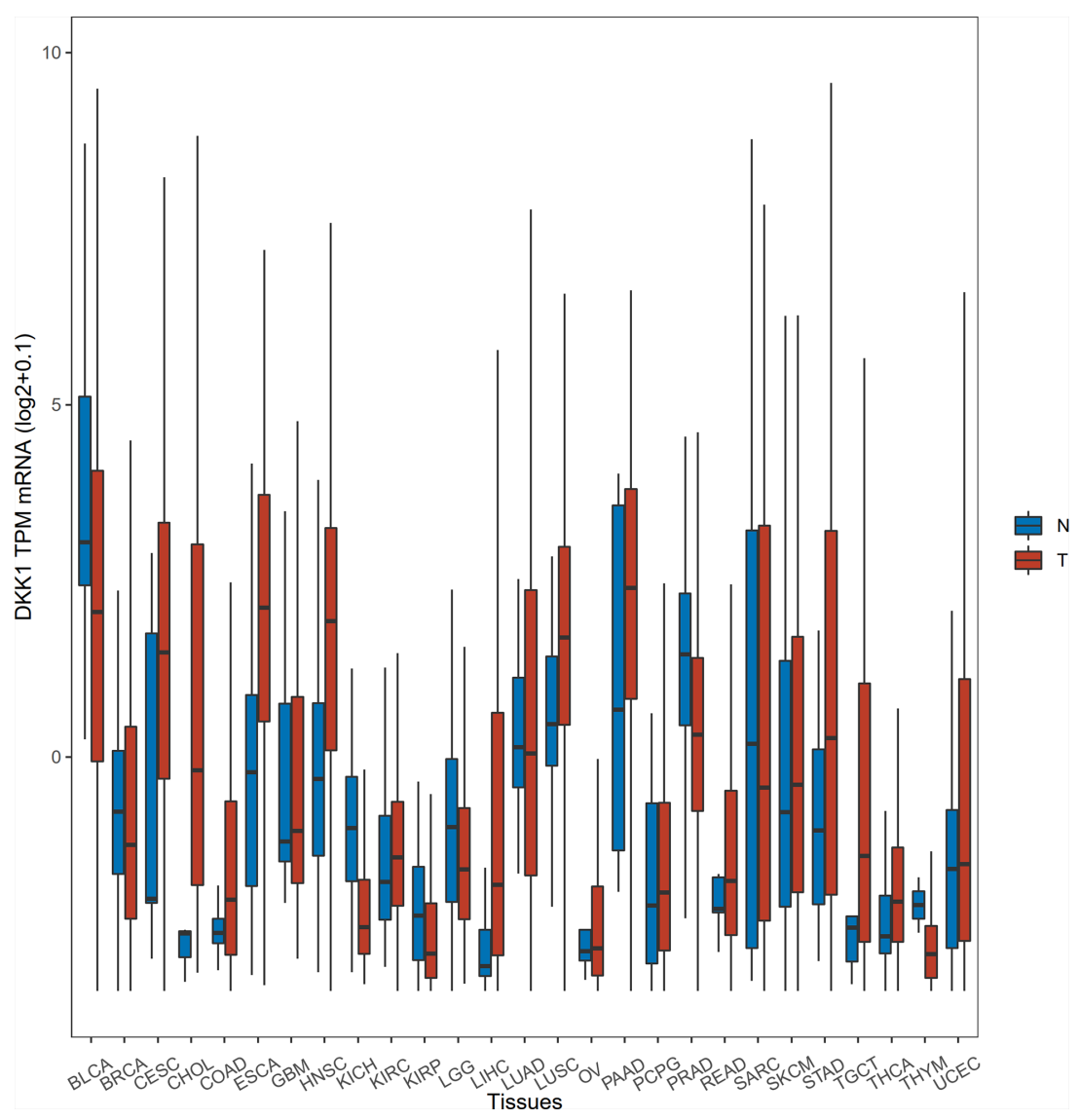

FIGURE 1 | Differential expression of DKK1 in different disease states. The horizontal bars from bottom to top within the box represent the 25th percentiles, median, and 75th percentiles of the normalized DKK1 TPM mRNA. The upper and lower ends of vertical line correspond to the maximum and minimum of the normalized DKK1 TPM mRNA.

\section{THE ROLE OF DKK1 IN MODULATING CANCER CELLS \\ Cancer-Promoting Effects of DKK1 in Cancer Models}

Beyond the potential to be a diagnostic indicator, DKK1 has been viewed as a promising target for anti-cancer therapy due to its cancer-promoting activity existing in preclinical cancer models (Table 2). In these in vitro models, DKK1 could contribute to tumor progression by promoting migration, invasion, proliferation, preventing apoptosis and enhancing cancer stem cell-like properties. In addition, DKK1 had tumor-promoting activity in in vivo animal models through its effects on tumor growth, metastasis, and angiogenesis.

Emerging evidence has improved our understanding of how DKK1 could promote tumor growth and metastasis through the modulation of signaling pathways in cancer cells. For example, a recent study has demonstrated that DKK1 promoted metastasis in an in vivo model attributed to its function of inhibition of $\beta$-catenindependent Wnt signaling (24). Latency competent cancer (LCC) cells showed stem cell-like characteristics and expressed Sry-box transcription factor 2 (SOX2) and Sry-box transcription factor 9 (SOX9) transcription factors, which were critical for their survival in host organs under immune surveillance and for metastatic outgrowth under permitted conditions. In the observation of LCC cells isolated latency from early-stage human lung and breast carcinoma cell lines, these cells were found to enter quiescence by self-imposing a slow-cycling state to avoid immune surveillance. Impeding DKK1 expression would re-sensitize these LCC cells to $\beta$ catenin-dependent Wnt signaling and upregulate the expression of activating ligands for NK cells, leading to NK cell-mediated clearance of the LCC cells and reduced metastasis. The result implied that the reactivation of $\beta$-catenin-dependent Wnt signaling, in a way that suppressed DKK1, could contribute to the elimination of LCC cells and thereby prevent tumor metastasis. Corresponding to the impact on stem cell-like LCC cells, DKK1 could favor the formation of an undifferentiated phenotype via inhibiting $\beta$-catenin-dependent Wnt signaling. For example, DKK1 antibody restored $\beta$-catenin-dependent Wnt signaling and promoted phenotype differentiation in osteosarcoma, leading to less distant metastases (64). Cancer stem cells have been linked to cancer metastases and drug resistance due to their early existence 
TABLE 2 | The effects of DKK1 in cancer model and immune response.

\section{Cell Culture Model}

Breast

Intrahepatic

Cholangiocarcinoma (ICC)

Human hilar

cholangiocarcinoma

Hepatocellular carcinoma

Multiple myeloma

Colorectal

Small cell lung cancer

Non-small cell lung cancer

Lung and pancreatic

Osteosarcoma

Esophageal

In Vivo Animal Model

Breast

Breast and lung

Human hilar

cholangiocarcinoma

Multiple myeloma

Small cell lung cancer

Non-small cell lung cancer

Lung and pancreatic

cancer

Osteosarcoma

Hepatocellular carcinoma

Prostate cancer

Types of immune cells

MDSCs

$\mathrm{T}$ cells

NK cells and $\mathrm{CD}^{+} \mathrm{T}$ cells

DCs and $\mathrm{CD}^{+} \mathrm{T}$ cells

MDSCs and CD45 ${ }^{+}$cells

CD4+ and CD8+ T cells
DKK1 enhanced ECFC proliferation while DKK1 silencing suppressed their angiogenic potential.

DKK1was highly expressed by human breast cancer cell lines with osteolytic bone features.

DKK1 enhanced tumor cell invasion and promoted lymph node metastasis through the induction of MMP9 and VEGF-C.

Depletion of DKK1 led to repression of cell proliferation and migration in part through the $\beta$-catenin/MMP-7 signaling pathway.

DKK1 promoted HCC cell migration and invasion partly by regulating $\beta$-catenin/MMP7 signaling axis.

Deletion of DKK1 suppressed cell migration and invasion while its overexpression showed opposite effect.

Anti-DKK1 antibody hindered MM cell growth by regulating the bone marrow microenvironment.

DKK1 located in the nucleus of human colorectal cancer cells involved in cancer-related target gene transcription.

Reduced expression of DKK1 induced inhibition of cancer cell proliferation, colony formation, migration and invasion.

Anti-DKK1 antibody suppressed cancer growth and invasive activity.

Knockdown of DKK1 in cancer cells inhibited cancer cell proliferation and migration.

DKK1 expression promoted cancer cell expansion and increased tumor stress metabolic resistance for its upregulation of ALDH levels.

DKK1 knockdown inhibited cell proliferation, colony formation and stem cell-like characteristics including downregulation of ALDH1A1 and CK18 expression.

DKK1 strongly enhanced the vascularization of Matrigel plugs and tumor growth.

Levels of Dkk-1 dramatically increased in bone marrow of inoculated mice.

DKK1 showed dichotomous role in metastasis organotropism as it inhibited lung metastasis and promoted bone metastasis at the same time.

DKK1 promoted malignant cell proliferation by facilitating LCC cells to enter quiescence and thus achieve immune surveillance.

DKK1 expression was positively correlated with tumor volume as well as MMP-7 expression.

Anti-DKK1 antibody resulted in diminished tumor growth and prevented bone loss.

Humanized anti-DKK1 antibody demonstrated significant anti-MM effect.

A neutralizing DKK1 antibody reduced primary myeloma burden and increased bone formation. Interfering with DKK1 helped prevent bone metastasis.

Anti-DKK1 antibody inhibited tumor growth.

DKK1 knockdown suppressed tumor formation

DKK1 expression led to increased tumor formation and deterioration.

DKK1 responded to the treatment of anti-DKK1 antibody BHQ880 with decreased tumor growth rate and metastasis.

(25)

DKK1 increased tumor burden as well as bone metastasis.

Regulatory activities

DKK1 contributed to MDSC accumulation and tumor progression in vivo by reducing $\beta$-catenin levels.

Reference

The increased circulating amounts of DKK1 polarized T cells to Th2 cells, which was mediated by the kinases p38 MAPK and SGK-1, leading to Th2 cell cytokine production.

Overexpression of DKK1 could modulate the anti-tumor immune populations within the tumor mice.

Anti-tumor efficacy of anti-DKK1 DNA vaccine in mice model required the function of $C D 8^{+} \mathrm{CD} 11 \mathrm{c}^{+}$dendritic cells (DCs) during tumorigenesis and reversible states from active to quiescence (72). The function of DKK1 on cancer cells with stem/progenitor cell features suggests that DKK1 may be involved in cancer stem cells-related phenotype development and cancer cell dissemination. Some concerns have arisen since re-activation of phenotype cells may also induce proliferation of the cells themselves and, in principle, increase tumor growth. How to enhance tumor immune surveillance without promoting tumor growth is an important issue to be addressed.
Another recent study demonstrated the ability of DKK1 to facilitate invasive cell behaviors by increasing mesenchymal characteristics in receptive cells. DKK1 was proven to be involved in disturbing cell cohesion and altering cell polarity, resulting in unsuccessful cell-cell adhesion and coordinated progression. This cell interaction control was independent of $\beta$-catenin transcriptional output and Wnt/PCP signaling (73). Additionally, the Janus-faced molecules feature of DKK1 in organotrophic metastasis was deciphered in another study (62). In breast cancer, tumor-secreted 
DKK1 suppressed lung metastasis by downregulating PTGS2induced macrophage and neutrophil recruitment by antagonizing non-canonical SOX2 and SOX9 signaling. In the lungs, DKK1 also reduced the latent transforming growth factor-beta binding protein1 (LTBP1)-mediated transforming growth factor-beta (TGF- $\beta$ ) secretion of cancer cells by inhibiting $\mathrm{Wnt} / \mathrm{Ca}^{2+}$-calmodulindependent protein kinase II) (CaMKII)-Nuclear factor- $\mathrm{kb}$ (NF$\kappa \mathrm{B})$ signaling. In contrast, DKK1 promoted breast-to-bone metastasis by regulating canonical Wnt signaling of osteoblasts. Given that the TGF- $\beta$ signaling pathway was also of great importance for osteolytic metastasis (74), it was intriguing to observe that suppression of LTBP1 and TGF- $\beta$ under DKK1 overexpression did not interfere with bone metastasis. This obvious inconsistency could be interpreted by the rich reservoir of TGF- $\beta$ in bone matrix and thus the reduced TGF- $\beta$ of DKK1expressing tumor cells may be easily compensated. These results suggest that the combinatory targeting strategy of non-canonical Wnt signaling that included JNK and TGF instead of canonical Wnt signaling may be more beneficial for metastatic diseases therapy. In view of this, the therapeutics approach against DKK1 should be examined regarding the dichotomous function of DKK1 in cancer metastasis organotropism.

\section{THE ROLE OF DKK1 IN MODULATING THE IMMUNE CELLS}

\section{Correlation Between DKK1 Expression and Tumor-Infiltrating Lymphocytes}

Previous analyses implied tumor-infiltrating lymphocytes could be independent predictors of sentinel lymph node status and survival in cancer patients (75). To have a clear understanding of the relation between DKK1 and immune infiltrates across a spectrum of cancer types, we employed the TIMER2.0 as a comprehensive resource for systematic analysis (http://timer.comp-genomics.org/) (76). TIMER applies a previously published statistical approach called deconvolution that uses gene expression profiles to produce an inference in the number of tumor-infiltrating immune cells. TCGA provides the TIMER database 10,897 samples across 40 cancer types, which are applied for the approximation of immune infiltrates. We inquired on the mRNA expression of DKK1 in different types of cancers and its correlation with the abundance of immune infiltrates. From the results, the expression level of DKK1 was significantly positively correlated with infiltrating levels of MDSCs in 20 types of cancers, suggesting DKK1 is involved in MDSCs modulation in a variety of cancers (Figure 2). More importantly, there was a negative correlation between levels of DKK1 and $\mathrm{CD}^{+} \mathrm{T}$ cells in the corresponding carcinomas, including HNSC, TGCT, CESC, and LUSC. MDSCs were defined as the heterogeneous population of immature myeloid cells recruited by tumors, which could induce $\mathrm{CD} 8^{+} \mathrm{T}$ cell tolerance in tumor-bearing hosts despite seemingly adequate infiltration by $\mathrm{CD}^{+} \mathrm{T}$ cells and interferon-responsive tumor cells (77). Results of the analysis indicated DKK1 may induce MDSC accumulation and $\mathrm{T}$ cell dispersal during tumor progression.

\section{Immunoregulatory Effects of DKK1}

Activation of the Wnt signaling pathway directly regulated the function of immune cells including dendritic cells, macrophages, myeloid-derived suppressor cells and T lymphocytes (78). The confirmed Wnt signaling inhibitor DKK1 was consequently assumed to intervene in immune cell activities. Recently, DKK1
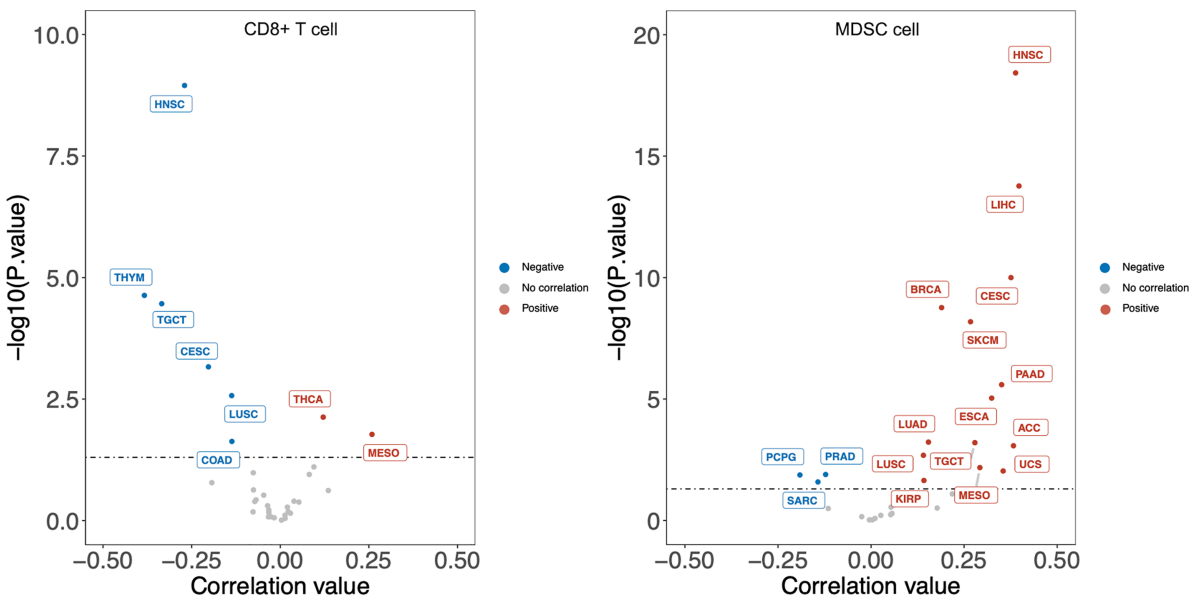

FIGURE 2 | DKK1 expression level has significant negative correlation with infiltrating levels of CD8 ${ }^{+} \mathrm{T}_{\text {cells }}$ and positive correlation with MDSC cells in various cancers. According to the results, the expression level of DKK1 was positively correlated with infiltrating levels of MDSCs in 20 types of cancers, and negatively correlated with levels of CD8+ T cells in 6 types of cancers. Cancers that fit these two relations include HNSC, TGCT, CESC, and LUSC. HNSC, Head-Neck Squamous Cell Carcinoma; THYM, Thymoma; TGCT, Testicular Germ Cell Tumors; CESC, Cervical Squamous Cell Carcinoma and Endocervical Adenocarcinoma; LUSC, Lung Squamous Cell Carcinoma; COAD, Colon Adenocarcinoma; THCA, Thyroid carcinoma; MESO, Mesothelioma; LIHC, Liver Hepatocellular Carcinoma; BRCA, Breast Invasive Carcinoma; SKCM, Skin Cutaneous Melanoma; PAAD, Pancreatic Adenocarcinoma; ESCA, Esophageal Carcinoma; LUAD, Lung Adenocarcinoma; ACC, Adrenocortical Carcinoma; UCS, Uterine Carcinosarcoma; KIRP, Kidney Renal Papillary Cell Carcinoma; PRAD, Prostate Adenocarcinoma; PCPG, Pheochromocytoma and Paraganglioma; SARC, Sarcoma. 
was proposed as an indicator of inflammatory responses for its elevated levels in patients with infections or hematological disorders $(79,80)$. In the allergen challenge model, DKK1 enhance type 2 inflammation response and T helper 2 (Th2) cell polarization via serum glucocorticoid kinase (SGK)-1 and p38 mitogen-activated protein kinases (MAPK) in $\mathrm{CD}^{+}{ }^{+} \mathrm{T}$ cells, while reducing $\mathrm{T}$ helper 1 (Th1) cytokine production (66). For instance, DKK1 suppressed interferon- $\gamma(\mathrm{IFn}-\gamma)$ from $\mathrm{CD} 4^{+} \mathrm{T}$ cells while elevating the secretion of Th2 cytokine including interleukin (IL)-4, IL-5, IL-10, and IL-13. The same preferential shift of Th1 to Th2 cells has also been found in the carcinogenesis process (81). Interestingly, inflammation driven by tumour-specific Th1 call is currently believed to prevent cancers but Th2 subset seems to have an opposite function (82). Th1-mediated interferon- $\gamma$ (IFn- $\gamma$ ) is proved to be necessary for facilitating macrophages to kill cancer cells and up-regulating MHC molecules on cancer cells leading to enhance T cell recognition (83, 84). On the other hand, the Th2-type cytokine pattern is more preferential in the malignant tumor and participated in cancer progression and immune evasion (85-87). In addition, Chae's work also revealed that platelets are the source of circulating DKK1 (66). Preclinical and clinical studies shows that platelets have a crucial role in tumorigenesis, metastasis, and cancer evasion of immune surveillance $(88,89)$. Based on these studies, platelet-derived DKK1 may be a pro-tumorigenic factor due to its various crosstalk with immune cells. Besides involving in modulation of $\mathrm{T}$ helper cell development, DKK1 was also proven to be a key player in tumor microenvironment through MDSCs manipulation. D'Amico et al. found that DKK1 was highly expressed in circulation and bone environments in syngeneic murine tumor models such as melanoma and Lewis lung carcinoma models, and the dominant source of DKK1 could be specific to bone-resident osteoblasts (90, 91). In this study, antibody-mediated neutralization of DKK1 resulted in a marked reduction of MDSCs expansion and tumor progression. The mechanism could be illustrated by the inhibition of $\beta$-catenin by DKK1 leading to accumulation of MDSCs and increasing their ability to suppress $\mathrm{T}$ cell activation and proliferation. Supporting this potential mechanism, Capietto et al. previously showed that DKK1-drived downregulation in $\beta$-catenin drives MDSC accumulation in the bone marrow, spleen, and at primary tumor sites, and controls their immune suppressive effects (91).

A recent study reveals that overexpression of DKK1 could modulate anti-tumor immune populations within the tumor microenvironment by decreasing $\mathrm{CD} 45^{+}$leukocyte infiltration and reducing $\mathrm{NK}$ and $\mathrm{CD}^{+} \mathrm{T}$ cells (67). On the other hand, a novel anti-tumor DNA vaccine designed by Guo's team stressed the significance of the role of $\mathrm{CD}^{+}$cells in the effect of DKK1 on tumor immunosuppression (68). The vaccine targeting PD-L1 and DKK1 showed efficacy in the mice model of multiple myeloma, which required the function of $\mathrm{CD}^{+} \mathrm{CD} 11 \mathrm{c}^{+}$ dendritic cells and $\mathrm{CD}^{+} \mathrm{T}$ cells. To summarize, DKK1 had immunoregulatory effects, including promoting Th2 cells response, reducing the functionality of $\mathrm{T}$ cells through MDSC modulation and suppressing the proliferation of $\mathrm{CD}^{+} \mathrm{T}$ cells and NK cells, thus contributing to inflammatory response and cancer immune evasion. Although there has been a more detailed and clear description of the participation of DKK1 in immune response due to recent research, an investigation of how DKK1 manipulates different immune responses to exert anti-tumor effects is necessary. Active Wnt signaling pathway plays an essential role in $\mathrm{T}$ cell and $\mathrm{B}$ cell development, for example, mice with deficient for the Wnt-responsive transcription factors TCF1 and Lymphoid enhancer-binding factor 1 (LEF1) showed defects in T cell and B cell development (92) (93). Nonetheless, how the Wnt antagonist DKK1 could intervene in these cell processes is still poorly understood. More direct evidence is required to elucidate the mechanism of how DKK1 modulates immune cells for immunosuppression.

\section{Potential Role of DKK1 in Regulating Therapeutic Response of Immune Checkpoint Inhibitors}

Some nonclinical studies for developing anti-DKK1 drugs have provided clues to reveal the pivotal role of DKK1 in regulating therapeutic response of immune checkpoint inhibitors. For example, the activity of the anti-DKK1 antibody DKN-01 was dependent on a functional immune system in the murine cancer model. Furthermore, DKN-01 induced reduction in MDSCs and upregulation in $\mathrm{CD} 45^{+}$cells in the tumor microenvironment (69). This evidence suggested DKK1 would participate in anti-tumor immunomodulation. Local immunosuppressive factors within the tumor microenvironment, including MDSCs, were regarded as one of the mechanisms of primary resistance of PD-1/PD-L1 therapy. MDSCs were defined as the heterogeneous population of immature myeloid cells recruited by tumors, which were able to impair response to a PD-1/PD-L1 blockade despite seemingly adequate infiltration by $\mathrm{CD}^{+} \mathrm{T}$ cells and interferon-responsive tumor cells (77). Possibly, the DKK1 antibody could act on MDSCs to exploit the supportive tumor microenvironment by preventing MDSC accumulation and compromising their inhibitory effect on immune cells. In addition, some innovative inhibitory strategies against DKK1 have been reported. Park et al. generated a cyclic oligopeptide that could inhibit Wnt signaling pathway and reduce tumor burden in vivo (94). A fusion DNA vaccine composed of DKK1 and human HSP70 developed by Liu et al. and a DKK1 DNA vaccine produced by Qian et al. also consistently demonstrated therapeutic efficacies on murine multiple myeloma $(70,71)$. In the latter study, injection of the DKK1 vaccine not only repressed tumor growth, but also enhanced $\mathrm{CD}^{+}$and $\mathrm{CD}^{+} \mathrm{T}$ cell response toward cancer cells. Further understanding of DKK1 in immunotherapy requires more experimental evidence, which may prompt the use of DKK1 antibody in combination with other existing immunotherapeutic drugs to achieve better efficacy.

\section{DEVELOPMENT OF ANTI-DKK1 THERAPY}

\section{Anti-DKK1 Antibody in Clinical Trials}

DKK1's suppressive effect on the immune system made it a promising target for immunotherapy. Recently, the anti-DKK1 
neutralizing antibody DKN-01, which is developed by Leap Therapeutics, are being evaluated in phase I or phase II trials of advanced gastroesophageal junction and gastric cancer (GEJ/ GC) and gynecologic cancers, in the form of both monotherapy and combination therapy with paclitaxel or pembrolizumab. In the phase II trials of advanced gynecologic malignancies (relapsed or refractory epithelial endometrial cancer, epithelial ovarian cancer, or carcinosarcoma: NCT03395080), the overall response rate (ORR) of DKN-01 monotherapy was $7 \%$ while that of combination with paclitaxel was $4 \%$ (95). Of note, gynecologic cancer patients with Wnt signaling mutations were beneficial from DKN-1 treatment (96). The other ongoing clinical study of GEJ/GC demonstrated improved survival and objective response outcomes especially in patients whose tumors expressed high levels of DKK1 (DKK1-high) (97). DKN-01 plus Keytruda (pembrolizumab) combination therapy was used to treat sixtythree patients in all different arms and dose. Around $84 \%$ patients had never undergone PD-1/PD-L1 therapy before, and ten were PD-1/PD-L1 treatment refractory. All patients in the study had been heavily pretreated, with one to five lines of therapy already administered. The highly encouraging results stated that DKN-01 plus Keytruda therapy resulted in a median progression-free survival (PFS) over 22 weeks and a median overall survival (OS) nearly 32 weeks, with a $50 \%$ ORR and $80 \%$ disease control rate (DCR) in patients with DKK1-high GEJ/GC who had not received prior anti-PD-1/PD-L1 therapy. Among the six GEJ/GC patients who were refractory to PD-1/PD-L1 therapy, three patients with high serum levels of DKK1 had the best response of stable disease, whereas the three patients with low serum levels of DKK1 had progressive disease (97). The results revealed that DKK1 inhibition therapy significantly improved the responsiveness of patients with high serum levels of DKK1 and suggested the strategy to achieve better efficacy using DKK1 inhibitor along with PD1/PDL-1 immune checkpoint treatment in patients who have DKK1-high tumors. Another DKK1 antibody BHQ880, developed by Novartis Pharmaceuticals, had completed phase $1 \mathrm{~B}$ trials in multiple myeloma. Despite some observed clinical benefits, $96.4 \%$ patients $(n=28)$ reported adverse events (AE) with one-third of these reported events suspected to be related to either the antibody or zoledronic acid. The suspected study drug related AEs include hypertension $(n=2)$, increased serum creatinine $(n=1)$ and thrombocytopenia $(n=1)$. Further clinical studies are needed to evaluate these monoclonal antibodies' efficacy and safety in the treatment of individual cancer. More significantly, given its unsatisfactory performance relative to combination therapy, how to enhance the therapeutic efficacy of DKK1 antibody monotherapy was an important topic, in which understanding the functional mechanism as well as the $3 \mathrm{D}$ structure of DKK1 could provide potential directions.

\section{Function of DKK1 Domains and Prediction of the 3D Structure of DKK1}

DKK1 consisted of five domains, including signal sequence, Linker 1 (L1), the amino-terminal cysteine-rich domain (termed N), Linker 2 (L2), and the carboxyl terminal cysteinerich domain (termed C) (2) (Figure 3). So far, several studies focused on the functional mechanism of the feature cysteine-rich $\mathrm{N}$ domain and $\mathrm{C}$ domain have been conducted. Crystal structure demonstrated that $\mathrm{C}$ domain and $\mathrm{N}$ domain bind to the four $\beta$ propeller and EGF-like domain repeats of LRP6 ectodomain, respectively (98). Because these domain repeats were capable of binding to several Wnt variants, a single DKK1 molecule may bind to all portions of the LRP6 ectodomain and thereby inhibit different Wnt pathways. The $\mathrm{C}$ domain was regarded as the critical binding site for Wnt signaling inhibition and the antibody DKN-01 could specifically recognize the $\mathrm{C}$ domain of DKK1 (100). More strikingly, a study on Wnt signaling in Xenopus embryos assessed distinct functional activities of these two functional domains. The $\mathrm{C}$ domain was shown to be necessary and sufficient for Wnt inhibition, while the $\mathrm{N}$ domain regulated this interaction by masking the ability of the C domain to synergize with LRP6 (101). On the other hand, the function of the $\mathrm{N}$ domain was more perplexing. It was defined as a signal domain that was responsible for the potent effects of DKK1 on heart-induction when synergizing with Wnt antagonists (102). CKAP4 was originally known as a protein that mainly localized to the endoplasmic reticulum and is now also defined as a novel DKK1 receptor. In the case of DKK1/ CKAP4 signaling pathway, the $\mathrm{N}$ domain was found to be required for DKK1 binding to CKAP4 and thereby activated AKT by forming a complex between the leucine zipper domain of CKAP4 and the Src homology 3 domain of PI3K, resulting in cellular proliferation (26). This finding suggested that the $\mathrm{N}$ domain along with canonical Wnt inhibitor may play a crucial role in the numerous developmental and disease processes that involve DKK1. From this result, DKK1 may self-regulate its inhibitory effect on the Wnt signaling pathway. One possibility was that the $\mathrm{N}$ domain interacted with the $\mathrm{C}$ domain, thereby inhibiting its ability to synergize with LRP6. Furthermore, the

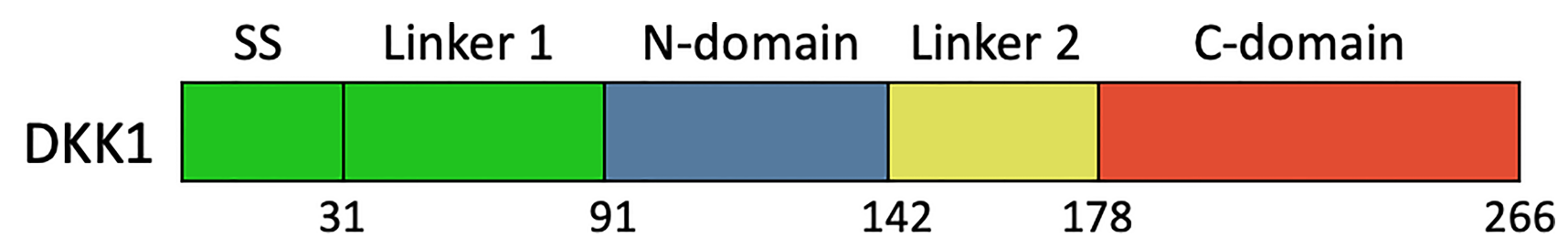

FIGURE 3 | Schematic diagram of the primary structures of full length DKK1. SS, signal sequence; N-domain and C-domain, two conserved cysteine-rich domains; L1, N1, L2, C1, named domain construct. 
post-translational modification of DKK1 protein may provide some useful hints. Ten disulfide bonds were detected in DKK1 molecule with five in the $\mathrm{N}$ domain and five in the $\mathrm{C}$ domain (102). Interesting, the disulfide topographic arrangement in the same domain is similar, while the overall pattern of all five disulfide bonds in these two domains is apparently different, suggesting that the two domains may have a different role in DKK1 function. There are nine reported glycosylation sites including the $O$-linked glycosylation at Ser61, Thr155, Ser163, Thr164, Ser169, Thr172, Thr173, Thr181, and N-linked glycosylation Asn256, which may interferes with the secretion of protein (103-105). Moreover, the L 1 and L2 domains may also be involved in controlling the protein conformation.

For the purpose of further depicting the functional mechanism of DKK1, it is essential to explore the roles of different domains. However, no three-dimensional protein structure of full length DKK1 was reported at present. According to the existing reports mentioned, we hypothesized that DKK1 could form distinct conformations with different intermolecular interactions between $\mathrm{C}$ domain and $\mathrm{N}$ domain, resulting in differences in the intramolecular interactions with LRP6 and CKAP4, respectively. To have a better understanding of DKK1 structure, we predicted the 3D structure of full length DKK1 by homology modeling and calculate the inter-molecular interactions between domains within DKK1. ORION was employed for predicting protein $3 \mathrm{D}$ structure and this method relies on the descriptors called Protein Blocks (PB) to encode a structural alphabet defined by 16 local structural patterns that accurately describe local protein structures $(58,106)$. Interactions between two residues were defined when the atoms distance was $<4 \AA$, and strong interactions between two residues were defined when the atoms distance was $<3 \AA$. According to the modeling results, DKK1 mainly formed two different 3D structures (Figure 4 and Table 3). One was a circular conformation with no interactive residues between $\mathrm{C}$ domain and $\mathrm{N}$ domain but considerable interactive residues between $\mathrm{N}$ domain and L2 (five pairs of strongly interactive residues), which could hinder the interaction between $\mathrm{N}$ domain
TABLE 3 | The inter-molecular interactions among domains within DKK1.

\begin{tabular}{|c|c|c|c|c|}
\hline \multirow[t]{2}{*}{ Domain } & \multicolumn{2}{|c|}{ Structure 1} & \multicolumn{2}{|c|}{ Structure 2} \\
\hline & Residues pair & Distance (Å) & Residues pair & Distance (A) \\
\hline \multirow[t]{12}{*}{ Link 2 \& N } & $E-149 \&$ C-114 & 3.2 & L-174 \& R-102 & 2.9 \\
\hline & I-150 \& C-114 & 3.5 & K-177 \& R-102 & 3.0 \\
\hline & I-150 \& L-112 & 3.1 & N-177 \& P-100 & 3.1 \\
\hline & $E-151 \& P-100$ & 3.8 & N-144 \& S-140 & 2.6 \\
\hline & E-151 \& L-112 & 3.0 & / & / \\
\hline & E-152 \& L-112 & 3.0 & / & / \\
\hline & $Y-168$ \& I-137 & 2.9 & / & / \\
\hline & $\mathrm{H}-162$ \& V-139 & 2.8 & / & / \\
\hline & $\mathrm{R}-170$ \& R-102 & 3.0 & / & / \\
\hline & L-174 \& G-104 & 3.4 & / & / \\
\hline & L-174 \& Y-132 & 3.6 & / & / \\
\hline & S-176 \& C-133 & 3.2 & / & / \\
\hline \multirow[t]{21}{*}{$C \& N$} & / & / & Y-179 \& A-98 & 3 \\
\hline & / & / & $Y-179 \& P-100$ & 3 \\
\hline & / & / & H-180 \& E-95 & 3.3 \\
\hline & / & / & V-188 \& C-97 & 3.1 \\
\hline & / & / & S-193 \& A-98 & 2.7 \\
\hline & / & / & $\mathrm{R}-224$ \& M-126 & 2.9 \\
\hline & / & / & $\mathrm{S}-228$ \& N-131 & 2.6 \\
\hline & / & / & L-231 \& R-115 & 3.1 \\
\hline & / & / & $E-232 \& A-113$ & 2.6 \\
\hline & / & / & E-232 \& R-118 & 2.7 \\
\hline & / & / & E-232 \& R-119 & 2.9 \\
\hline & / & / & I-233 \& C-128 & 3.0 \\
\hline & / & / & $\mathrm{I}-233 \& \mathrm{H}-124$ & 3.4 \\
\hline & / & / & I-233 \& M-126 & 3.3 \\
\hline & / & / & F-234 \& C-121 & 3 \\
\hline & / & / & F-234 \& R-120 & 3.7 \\
\hline & / & l & I-233 \& C-128 & 3 \\
\hline & / & / & Q-235 \& H-124 & 3.1 \\
\hline & / & / & Q-235 \& C-127 & 2.7 \\
\hline & / & / & $\mathrm{R}-236$ \& A-125 & 3.3 \\
\hline & / & / & Q-237 \& A-125 & 3.4 \\
\hline
\end{tabular}

Texts in red indicate the strongly effective interaction sites with inner distance less than $3 \AA$.

and $\mathrm{C}$ domain. The other was a closed conformation with most interactions forming between $\mathrm{N}$ domain and $\mathrm{C}$ domain (11 pairs of strongly interactive residues). The interactive residues between $\mathrm{N}$ domain and L2 was less than that in the circular conformation
A

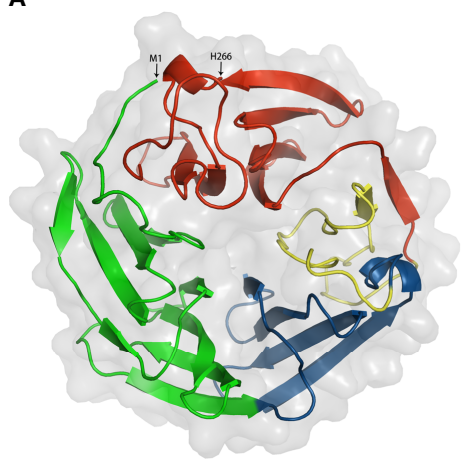

B

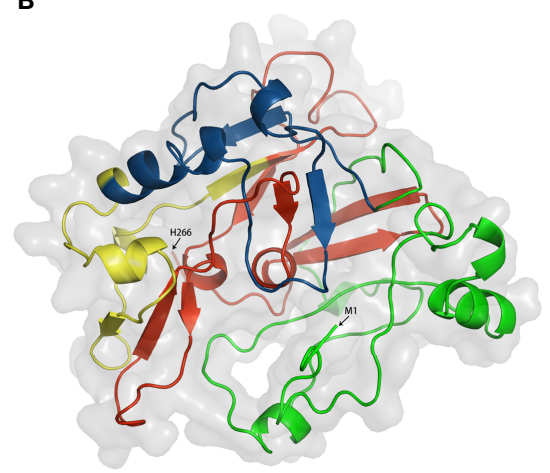

FIGURE 4 | Two modeling structures of DKK1. (A) a circular conformation; (B) a closed conformation. Green. Signal peptide (1-31); Link1 domain (32-91); Blue, N domain (92-142); yellow, Link2 domain (143-178); Red, C domain (179-266). Interactions between two residues were defined when the atoms distance was < $4 \AA$, and strong interactions between two residues were defined when the atoms distance was $<3 \AA$. 
(three pairs of strongly interactive residues). Since $\mathrm{N}$ domain was reported to diminish the binding of C domain to LRP6 (100), the closed conformation would be more desirable for impeding DKK1 from Wnt signal antagonizing. Moreover, these results suggested that the L2 domain of DKK1 may affect the 3D structure by competing with $\mathrm{C}$ domain for binding to $\mathrm{N}$ domain. Thus, intervening in the interaction between $\mathrm{L} 2$ and $\mathrm{N}$ domain may be a promising approach to facilitate the formation of the closed structure. Further functional studies are required to validate the results of the prediction and help to give a more insightful understanding of how the two domains of DKK1 interact structurally and thus provide insight into the development of more effective inhibitors. In addition, further exploration of the different configurations of these two regions and the interaction sites enable the intervention by specifically targeting inhibitors to achieve the ideal configuration of DKK1. This could provide a strong basis for developing advance DKK1 inhibitors with high anti-tumor efficacy.

\section{Conclusions and Perspectives}

Overall, DKK1 is an ideal anti-cancer therapeutic target for immunotherapy. Despite its role as clinical biomarker of cancer progression and prognosis, it also participated in multiple tumor deterioration in preclinical cancer models. The elevated serum level of DKK1 was observed in patients of various cancers with poor prognosis. According to gene profile analysis, mRNA level of DKK1 was overexpressed in a range of tumor types (14 out of 27 ). In addition to mRNA level, DKK1 protein level was found to be increased in both serum and in tissue samples in some specific cancers. There was a positive correlation between the mRNA level of CTNNB1 and DKK1 according to our calculation, supported by the similar evidence from protein expressions in several types of cancers, suggesting that the elevation of DKK1 may be attributed to overactivation of Wnt signaling. More studies are warranted to unravel the mechanism of DKK1 protein secretion and its existence in cancer. Preclinically, DKK1 was proven to promote proliferation, metastasis, and invasion in cancer cell lines and DKK1 inhibition showed efficacy on tumor regression in animal models. Furthermore, DKK1 demonstrated immunoregulatory impacts including encouraging Th1/Th2 shifts, promote an immunosuppressive tumor microenvironment that benefited MDSCs expansion and $\mathrm{T}$ cell suppression, reducing the functionality of $\mathrm{T}$ cells by MDSC modulation, and suppressing the proliferation of $\mathrm{CD}^{+} \mathrm{T}$ cells and NK cells, thus contributing to inflammatory response and cancer immune evasion. Although the functional mechanism of DKK1 has not yet been fully elucidated, its role in signaling pathways in cancers and

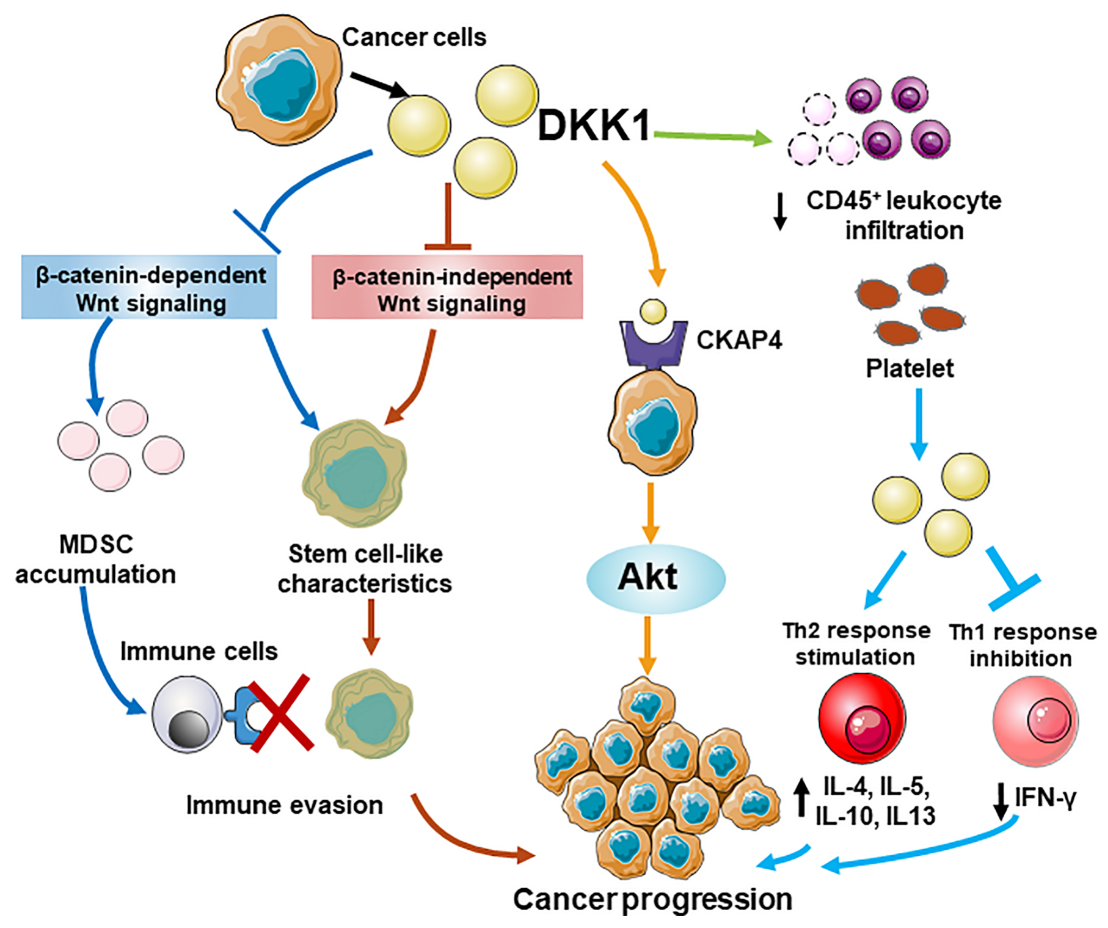

FIGURE 5 | A schematic model for different roles of DKK1 in immunomodulatory and tumorigenesis. DKK1 promotes an immunosuppressive tumor microenvironment that benefited MDSCs expansion by regulating $\beta$-catenin-independent Wnt signaling, and suppressing the proliferation of $\mathrm{CD}^{+} 5^{+} \mathrm{T}$ cells, thus contributing to cancer immune evasion. DKK1 helps cancer cells possess stem cell-like properties by preventing Wnt activation regardless of $\beta$-catenin dependence. A novel pathway shows DKK may interact with CKAP4 receptor, which lead to the activation of Akt signaling and increases the proliferation of the cancer cells. In the allergen challenge model, Platelet-derived DKK1 enhances Th2 response and elevates the secretion of IL-4, IL-5, IL-10, and IL-13, while suppresses Th1 response by reducing IFn- $\gamma$ expression. 
immune cells has become increasingly apparent. The engaging pathways include the canonical $\beta$-catenin-dependent Wnt signaling, $\beta$-catenin-independent $\mathrm{Wnt}$ signaling and the novel one involving CKAP4. Extra work is required to understand coordination of DKK1 in these pathways. A schematic model of different roles of DKK1 in immunomodulatory and tumorigenesis is illustrated (Figure 5). The latest findings from clinical trials of anti-DKK1 antibody DKN-01 also demonstrated that DKK1 is a potential candidate for treating advanced GEJ/GC and gynecologic cancers. The therapeutic strategy of developing a combination of DKK1 and immune checkpoint inhibitor based on precision medicine is promising for tumor patients with high DKK1 expression. As mentioned, DKK1 was highly expressed in a great variety of cancers and also involved in cancer progression. For instance, DKK1 was involved in bone metastases of small cell lung cancer cell model (58). It is reasonable to speculate that DKK1 could be a therapeutic approach for a wide range of malignancies. Based on these results and the increasing evidence of DKK1 tumor promoting activity, further clinical development is warranted. Another intriguing point in the clinical results is that in the combination treatment with DKN-1 and pembrolizumab, patients with a high DKK1 level in tumor demonstrated relatively higher efficacy than those with a low level. The same effect was observed in patients who were resistant to PD-1 treatment. Moreover, DKN-01 monotherapy had much less efficacy than that of combination therapy with anti-PD-1 antibody (51). With the aim to improve the performance of DKK1 monotherapy, it is imperative to elucidate the structural mechanism of DKK1 inhibition of the Wnt pathway. As mentioned, the $\mathrm{N}$ domain of DKK1 may be eligible to regulate the ability of its own $\mathrm{C}$ domain binding to LRP6. Our computational analysis results were consistent with this and pointed out the possibility of two distinct conformations of DKK1 structure with different interaction of $\mathrm{N}$ and $\mathrm{C}$ domain. Based on these points, we can study how different configurations of N-terminal domains of DKK1 affect the Wnt signaling pathway through interaction with the C-terminal domains

\section{REFERENCES}

1. Kagey M H, Xi H. Rationale for Targeting the Wnt Signalling Modulator Dickkopf1 for Oncology. Br J Pharmacol (2017) 174:4637-50. doi: 10.1111/bph.13894

2. Fedi P, Bafico A, Soria AN, Burgess WH, Miki T, Bottaro DP, et al. Isolation and Biochemical Characterization of the Human Dkk-1 Homologue, a Novel Inhibitor of Mammalian Wnt Signaling. J Biol Chem (1999) 274 (27):19465-72. doi: 10.1074/jbc.274.27.19465

3. Glinka A, Wu W, Delius H, Monaghan AP, Blumenstock C, Niehrs C. Dickkopf-1 is a Member of a New Family of Secreted Proteins and Functions in Head Induction. Nature (1998) 391(6665):357-62. doi: 10.1038/34848

4. Krupnik VE, Sharp JD, Jiang C, Robison K, Chickering TW, Amaravadi L, et al. Functional and Structural Diversity of the Human Dickkopf Gene Family. Gene (1999) 238(2):301-13. doi: 10.1016/S0378-1119(99)00365-0

5. Niehrs C. Function and Biological Roles of the Dickkopf Family of Wnt Modulators. Oncogene (2006) 25:7469-81. doi: 10.1038/sj.onc.1210054

6. Hameed A, Brady JJ, Dowling P, Clynes M, O'Gorman P. Bone Disease in Multiple Myeloma: Pathophysiology and Management. Cancer Growth Metastasis (2014) 7:33-42. doi: 10.4137/CGM.S16817

7. Aguilera Ó, González-Sancho JM, Zazo S, Rincón R, Fernández AF, Tapia O, et al. Nuclear DICKKOPF-1 as a Biomarker of Chemoresistance and Poor thereby discovering the new targeting domain on DKK1 for further drug development.

\section{AUTHOR CONTRIBUTIONS}

HC wrote and revised the manuscript. ZC performed the data analysis for DKK1 expression in cancers and the DKK1 structure prediction. HC, LW, Z-KZ, XT, SL, B-TZ, and AL contributed the manuscript for literature research. YY and GZ revised and approved the manuscript. All authors contributed to the article and approved the submitted version.

\section{FUNDING}

This study was supported by Hong Kong General Research Fund from the Research Grants Council of the Hong Kong Special Administrative Region, China (Project No. 12102120), Themebased Research Scheme from the Research Grants Council of the Hong Kong Special Administrative Region, China (Project No. T12-201/20-R), Basic and Applied Basic Research Fund from Department of Science and Technology of Guangdong Province (Project No. 2019B1515120089), Inter-institutional Collaborative Research Scheme from Hong Kong Baptist University (Project No. RC-ICRS/19-20/01) and UniversityIndustry Collaboration Programme from Innovation and Technology Commissions of the Hong Kong Special Administrative Region, China (Project No. UIM/328).

\section{ACKNOWLEDGMENTS}

We would like to thank Dr. Yixin He for the discussion and comments in manuscript preparation, and Mr. Youyang Wan for the assistance in DKK1 3D structure modeling.

Clinical Outcome in Colorectal Cancer. Oncotarget (2015) 6(8):5903-17. doi: 10.18632/oncotarget.3464

8. Mukhopadhyay M, Shtrom S, Rodriguez-Esteban C, Chen L, Tsukui T, Gomer L, et al. Dickkopf1 Is Required for Embryonic Head Induction and Limb Morphogenesis in the Mouse. Dev Cell (2001) 1(3):423-34. doi: 10.1016/S1534-5807(01)00041-7

9. Marvin MJ, Di Rocco G, Gardiner A, Bush SM, Lassar AB. Inhibition of Wnt Activity Induces Heart Formation From Posterior Mesoderm. Genes Dev (2001) 15(3):316-27. doi: 10.1101/gad.855501

10. Pinzone JJ, Hall BM, Thudi NK, Vonau M, Qiang YW, Rosol TJ, et al. The Role of Dickkopf-1 in Bone Development, Homeostasis, and Disease. Blood (2009) 113(3):517-25. doi: 10.1182/blood-2008-03-145169

11. Bafico A, Liu G, Yaniv A, Gazit A, Aaronson SA. Novel Mechanism of Wnt Signalling Inhibition Mediated by Dickkopf-1 Interaction With LRP6/ Arrow. Nat Cell Biol (2001) 3(7):683-6. doi: 10.1038/35083081

12. Mao B, Wu W, Li Y, Hoppe D, Stannek P, Glinka A, et al. LDL-ReceptorRelated Protein 6 is a Receptor for Dickkopf Proteins. Nature (2001) 411 (6835):321-5. doi: 10.1038/35077108

13. MacDonald BT, Tamai K, He X. Wnt/ $\beta$-Catenin Signaling: Components, Mechanisms, and Diseases. Dev Cell (2009) 17(1):9-26. doi: 10.1016/ j.devcel.2009.06.016 
14. Semënov MV, Tamai K, Brott BK, Kühl M, Sokol S, He X. Head Inducer Dickkopf-1 is a Ligand for Wnt Coreceptor LRP6. Curr Biol (2001) 11 (12):951-61. doi: 10.1016/S0960-9822(01)00290-1

15. Niida A, Hiroko T, Kasai M, Furukawa Y, Nakamura Y, Suzuki Y, et al. DKK1, a Negative Regulator of Wnt Signaling, is a Target of the $\beta$-Catenin/ TCF Pathway. Oncogene (2004) 23(52):8520-6. doi: 10.1038/sj.onc. 1207892

16. Matoba K, Mihara E, Tamura-Kawakami K, Miyazaki N, Maeda S, Hirai H, et al. Conformational Freedom of the LRP6 Ectodomain Is Regulated by Nglycosylation and the Binding of the Wnt Antagonist Dkk1. Cell Rep (2017) 18(1):32-40. doi: 10.1016/j.celrep.2016.12.017

17. Menezes ME, Devine DJ, Shevde LA, Samant RS. Dickkopf1: A Tumor Suppressor or Metastasis Promoter? Int J Cancer (2012) 130:1477-83. doi: $10.1002 /$ ijc. 26449

18. Zhan T, Rindtorff N, Boutros M. Wnt Signaling in Cancer. Oncogene (2017) 36(11):1461-73. doi: 10.1038/onc.2016.304

19. Sato H, Suzuki H, Toyota M, Nojima M, Maruyama R, Sasaki S, et al. Frequent Epigenetic Inactivation of DICKKOPF Family Genes in Human Gastrointestinal Tumors. Carcinogenesis (2007) 28(12):2459-66. doi: $10.1093 /$ carcin/bgm178

20. Hirata H, Hinoda Y, Nakajima K, Kawamoto K, Kikuno N, Ueno K, et al. Wnt Antagonist DKK1 Acts as a Tumor Suppressor Gene That Induces Apoptosis and Inhibits Proliferation in Human Renal Cell Carcinoma. Int $J$ Cancer (2011) 128(8):1793-803. doi: 10.1002/ijc.25507

21. Mikheev AM, Mikheeva SA, Maxwell JP, Rivo JV, Rostomily R, Swisshelm K, et al. Dickkopf-1 Mediated Tumor Suppression in Human Breast Carcinoma Cells. Breast Cancer Res Treat (2008) 112:263-73. doi: 10.1007/s10549-0079867-2

22. Zhao F, Xiao C, Evans KS, Theivanthiran T, DeVito N, Holtzhausen A, et al. Paracrine Wnt5a- $\beta$-Catenin Signaling Triggers a Metabolic Program That Drives Dendritic Cell Tolerization. Immunity (2018) 48:147-60.e7. doi: 10.1016/j.immuni.2017.12.004

23. Li X, Xiang Y, Li F, Yin C, Li B, Ke X. Wnt/ß-Catenin Signaling Pathway Regulating T Cell-Inflammation in the Tumor Microenvironment. Front Immunol (2019) 10:2293. doi: 10.3389/fimmu.2019.02293

24. Malladi S, MacAlinao DG, Jin X, He L, Basnet H, Zou Y, et al. Metastatic Latency and Immune Evasion Through Autocrine Inhibition of WNT. Cell (2016) 165(1):45-60. doi: 10.1016/j.cell.2016.02.025

25. Krause U, Ryan DM, Clough BH, Gregory CA. An Unexpected Role for a Wnt-inhibitor: Dickkopf-1 Triggers a Novel Cancer Survival Mechanism Through Modulation of Aldehyde-Dehydrogenase-1 Activity. Cell Death Dis (2014) 5:e1093. doi: 10.1038/cddis.2014.67

26. Kimura H, Fumoto K, Shojima K, Nojima S, Osugi Y, Tomihara H, et al. CKAP4 is a Dickkopf1 Receptor and is Involved in Tumor Progression. J Clin Invest (2016) 126(7):2689-705. doi: 10.1172/JCI84658

27. Igbinigie E, Guo F, Jiang SW, Kelley C, Li J. Dkk1 Involvement and its Potential as a Biomarker in Pancreatic Ductal Adenocarcinoma. Clin Chim Acta (2019) 488:226-34. doi: 10.1016/j.cca.2018.11.023

28. Liu QR, Li YF, Deng ZQ, Cao JQ. Prognostic Significance of Dickkopf-1 in Gastric Cancer Survival: A Meta-Analysis. Genet Test Mol Biomarkers (2016) 20:170-5. doi: 10.1089/gtmb.2015.0154

29. Forget MA, Turcotte S, Beauseigle D, Godin-Ethier J, Pelletier S, Martin J, et al. The Wnt Pathway Regulator DKK1 is Preferentially Expressed in Hormone-Resistant Breast Tumours and in Some Common Cancer Types. Br J Cancer (2007) 96(4):646-53. doi: 10.1038/sj.bjc.6603579

30. Wang S, Zhang S. Dickkopf-1 is Frequently Overexpressed in Ovarian Serous Carcinoma and Involved in Tumor Invasion. Clin Exp Metastasis (2011) 28(6):581-91. doi: 10.1007/s10585-011-9393-9

31. Yamabuki T, Takano A, Hayama S, Ishikawa N, Kato T, Miyamoto M, et al. Dikkopf-1 as a Novel Serologic and Prognostic Biomarker for Lung and Esophageal Carcinomas. Cancer Res (2007) 67:2517-25. doi: 10.1158/00085472.CAN-06-3369

32. Kasoha M, Bohle RM, Seibold A, Gerlinger C, Juhasz-Böss I, Solomayer EF. Dickkopf-1 (Dkk1) Protein Expression in Breast Cancer With Special Reference to Bone Metastases. Clin Exp Metastasis (2018) 35:763-75. doi: 10.1007/s10585-018-9937-3

33. Han Sx, Zhou X, Sui X, He Cc, Cai Mj, Ma J, et al. Serum Dickkopf-1 is a Novel Serological Biomarker for the Diagnosis and Prognosis of Pancreatic Cancer. Oncotarget (2015) 6(23):19907-17. doi: 10.18632/oncotarget.4529
34. Jiang T, Wang S, Huang L, Zhang S. Clinical Significance of Serum DKK-1 in Patients With Gynecological Cancer. Int J Gynecol Cancer (2009) 19:117781. doi: 10.1111/IGC.0b013e31819d8b2d

35. Rachner TD, Thiele S, Göbel A, Browne A, Fuessel S, Erdmann K, et al. High Serum Levels of Dickkopf-1 are Associated With a Poor Prognosis in Prostate Cancer Patients. BMC Cancer (2014) 14:649. doi: 10.1186/1471-2407-14-649

36. Shen Q, Fan J, Yang XR, Tan Y, Zhao W, Xu Y, et al. Serum DKK1 as a Protein Biomarker for the Diagnosis of Hepatocellular Carcinoma: A LargeScale, Multicentre Study. Lancet Oncol (2012) 13:817-26. doi: 10.1016/ S1470-2045(12)70233-4

37. Sun DK, Wang L, Wang JM, Zhang P. Serum Dickkopf-1 Levels as a Clinical and Prognostic Factor in Patients With Bladder Cancer. Genet Mol Res (2015) 14(4):18181-7. doi: 10.4238/2015.December.23.5

38. Shi LS, Huang G, Yu B, Wen XQ. Clinical Significance and Prognostic Value of Serum Dickkopf-1 Concentrations in Patients With Lung Cancer. Clin Chem (2009) 55(9):1656-64. doi: 10.1373/clinchem.2009.125641

39. Tian E, Zhan F, Walker R, Rasmussen E, Ma Y, Barlogie B, et al. The Role of the Wnt-Signaling Antagonist DKK1 in the Development of Osteolytic Lesions in Multiple Myeloma. N Engl J Med (2003) 349:2483-94. doi: 10.1056/NEJMoa030847

40. Lee N, Smolarz AJ, Olson S, David O, Reiser J, Kutner R, et al. A Potential Role for Dkk-1 in the Pathogenesis of Osteosarcoma Predicts Novel Diagnostic and Treatment Strategies. Br J Cancer (2007) 97:1552-9. doi: $10.1038 /$ sj.bjc.6604069

41. Colaprico A, Silva TC, Olsen C, Garofano L, Cava C, Garolini D, et al. Tcgabiolinks: An R/Bioconductor Package for Integrative Analysis of TCGA Data. Nucleic Acids Res (2016) 44(8):e71. doi: 10.1093/nar/gkv1507

42. Wei R, Rodriguez RA, Mullor M del MR, Tan Z, Gui Y, Hu J, et al. Analyzing the Prognostic Value of DKK1 Expression in Human Cancers Based on Bioinformatics. Ann Transl Med (2020) 8(8):552-2. doi: 10.21037/atm-20-3263

43. Chen C, Zhou H, Zhang X, Ma X, Liu Z, Liu X. Elevated Levels of Dickkopf-1 are Associated With $\beta$-Catenin Accumulation and Poor Prognosis in Patients With Chondrosarcoma. PLoS One (2014) 9(8):e105414. doi: 10.1371/journal.pone.0105414

44. Xu WH, Bin LZ, Yang C, Qin W, Shao ZM. Expression of Dickkopf-1 and Beta-Catenin Related to the Prognosis of Breast Cancer Patients With Triple Negative Phenotype. PLoS One (2012) 7(5):e37624. doi: 10.1371/ journal.pone.0037624

45. Yu B, Yang X, Xu Y, Yao G, Shu H, Lin B, et al. Elevated Expression of DKK1 is Associated With Cytoplasmic/Nuclear $\beta$-Catenin Accumulation and Poor Prognosis in Hepatocellular Carcinomas. J Hepatol (2009) 50:948-57. doi: 10.1016/j.jhep.2008.11.020

46. Shi X, Yu XH, Wu WR, Xu XL, Wang JY, Xu LB, et al. Dickkopf-1 Expression is Associated With Tumorigenity and Lymphatic Metastasis in Human Hilar Cholangiocarcinoma. Oncotarget (2016) 7:70378-87. doi: 10.18632 /oncotarget.11859

47. González-Sancho JM, Aguilera O, García JM, Pendás-Franco N, Peña C, Cal $\mathrm{S}$, et al. The Wnt Antagonist DICKKOPF-1 Gene is a Downstream Target of $\beta$-Catenin/TCF and is Downregulated in Human Colon Cancer. Oncogene (2005) 24(6):1098-103. doi: 10.1038/sj.onc. 1208303

48. He X, Li S, Luo X, Hu D, Cai T, Huang K, et al. Expression of DKK1 and $\beta$ Catenin in Epidermal Neoplasms and Their Correlation. Int J Clin Exp Med (2015) 8(10):18843-8.

49. Kane N, Jones M, Brosens JJ, Saunders PTK, Kelly RW, Critchley HOD. Transforming Growth Factor- $\beta 1$ Attenuates Expression of Both the Progesterone Receptor and Dickkopf in Differentiated Human Endometrial Stromal Cells. Mol Endocrinol (2008) 22(3):716-28. doi: 10.1210/me.2007-0316

50. Tulac S, Overgaard MT, Hamilton AE, Jumbe NL, Suchanek E, Giudice LC. Dickkopf-1, an Inhibitor of Wnt Signaling, is Regulated by Progesterone in Human Endometrial Stromal Cells. J Clin Endocrinol Metab (2006) 91 (4):1453-61. doi: 10.1210/jc.2005-0769

51. Smadja DM, D’Audigier C, Weiswald LB, Badoual C, Dangles-Marie V, Mauge L, et al. The Wnt Antagonist Dickkopf-1 Increases Endothelial Progenitor Cell Angiogenic Potential. Arterioscler Thromb Vasc Biol (2010) 30(12):2544-52. doi: 10.1161/ATVBAHA.110.213751

52. Voorzanger-Rousselot N, Goehrig D, Journe F, Doriath V, Body JJ, Clézardin P, et al. Increased Dickkopf-1 Expression in Breast Cancer Bone Metastases. Br J Cancer (2007) 97(7):964-70. doi: 10.1038/sj.bjc.6603959 
53. Shi RY, Yang XR, Shen QJ, Yang LX, Xu Y, Qiu SJ, et al. High Expression of Dickkopf-related Protein 1 is Related to Lymphatic Metastasis and Indicates Poor Prognosis in Intrahepatic Cholangiocarcinoma Patients After Surgery. Cancer (2013) 119:993-1003. doi: 10.1002/cncr.27788

54. Chen L, Li M, Li Q, Wang Cj, Xie Sq. DKK1 Promotes Hepatocellular Carcinoma Cell Migration and Invasion Through $\beta$-Catenin/MMP7 Signaling Pathway. Mol Cancer (2013) 12:157. doi: 10.1186/1476-4598-12-157

55. Tao YM, Liu Z, Liu HL. Dickkopf-1 (DKK1) Promotes Invasion and Metastasis of Hepatocellular Carcinoma. Dig Liver Dis (2013) 45(3):251-7. doi: $10.1016 /$ j.dld.2012.10.020

56. Pozzi S, Fulciniti M, Yan H, Vallet S, Eda H, Patel K, et al. In Vivo and In Vitro Effects of a Novel anti-Dkk1 Neutralizing Antibody in Multiple Myeloma. Bone (2013) 53(2):487-96. doi: 10.1016/j.bone.2013.01.012

57. Fulciniti M, Tassone P, Hideshima T, Vallet S, Nanjappa P, Ettenberg SA, et al. Anti-DKK1 mAb (BHQ880) as a Potential Therapeutic Agent for Multiple Myeloma. Blood (2009) 114:371-9. doi: 10.1182/blood-2008-11-191577

58. Pang H, Ma N, Jiao M, Shen W, Xin B, Wang T, et al. The Biological Effects of Dickkopf1 on Small Cell Lung Cancer Cells and Bone Metastasis. Oncol Res (2017) 25(1):35-42. doi: 10.3727/096504016X14719078133249

59. Yao L, Zhang D, Zhao X, Sun B, Liu Y, Gu Q, et al. Dickkopf-1-promoted Vasculogenic Mimicry in non-Small Cell Lung Cancer is Associated With EMT and Development of a Cancer Stem-Like Cell Phenotype. J Cell Mol Med (2016) 20:1673-85. doi: 10.1111/jcmm.12862

60. Sato N, Yamabuki T, Takano A, Koinuma J, Aragaki M, Masuda K, et al. Wnt Inhibitor Dickkopf-1 as a Target for Passive Cancer Immunotherapy. Cancer Res (2010) 70(13):5326-36. doi: 10.1158/0008-5472.CAN-09-3879

61. Lu Z, Zhou C, Hu J, Xiong L, Cong Z, Shen Y. DKK1 Maintained Cancer Stem-Like Properties of Esophageal Carcinoma Cells Via ALDH1A1/SOX2 Axis. Int J Clin Exp Pathol (2017) 10(9):9489-95.

62. Zhuang X, Zhang H, Li X, Li X, Cong M, Peng F, et al. Differential Effects on Lung and Bone Metastasis of Breast Cancer by Wnt Signalling Inhibitor DKK1. Nat Cell Biol (2017) 19(10):1274-85. doi: 10.1038/ncb3613

63. Yaccoby S, Ling W, Zhan F, Walker R, Barlogie B, Shaughnessy JD. Antibody-Based Inhibition of DKK1 Suppresses Tumor-Induced Bone Resorption and Multiple Myeloma Growth In Vivo. Blood (2007) 109:2106-11. doi: 10.1182/blood-2006-09-047712

64. Goldstein SD, Trucco M, Guzman WB, Hayashi M, Loeb DM. A Monoclonal Antibody Against the Wnt Signaling Inhibitor Dickkopf-1 Inhibits Osteosarcoma Metastasis in a Preclinical Model. Oncotarget (2016) 7:21114-23. doi: 10.18632/oncotarget.8522

65. Thudi NK, Martin CK, Murahari S, Shu ST, Lanigan LG, Werbeck JL, et al. Dickkopf-1 (DKK-1) Stimulated Prostate Cancer Growth and Metastasis and Inhibited Bone Formation in Osteoblastic Bone Metastases. Prostate (2011) 71(6):615-25. doi: 10.1002/pros.21277

66. Chae WJ, Ehrlich AK, Chan PY, Teixeira AM, Henegariu O, Hao L, et al. The Wnt Antagonist Dickkopf-Promotes Pathological Type 2 Cell-Mediated Inflammation. Immunity (2016) 44:246-58. doi: 10.1016/ j.immuni.2016.01.008

67. Betella I, Turbitt WJ, Szul T, Wu B, Martinez A, Katre A, et al. Wnt Signaling Modulator DKK1 as an Immunotherapeutic Target in Ovarian Cancer. Gynecol Oncol (2020) xxxx):1-10. doi: 10.1016/j.ygyno.2020.03.010

68. Guo S, Xiao P, Li B, Wang W, Wang S, Lv T, et al. Co-Immunizing With PDL1 Induces CD8+ Dcs-Mediated Anti-Tumor Immunity in Multiple Myeloma. Int Immunopharmacol (2020) 84:1-9. doi: 10.1016/ j.intimp.2020.106516

69. Haas M, Heath H, Schurpf-huber F, Newman L, Wu Y, Zhang X, et al. Dkn01 , a Therapeutic Dkk1 Neutralizing Antibody, Has Immune Modulatory Activity in Nonclinical Tumor Models. Am Assoc Cancer Res (2018) 78:1710. doi: 10.1158/1538-7445.AM2018-1710

70. Qian J, Zheng Y, Zheng C, Wang L, Qin H, Hong S, et al. Active Vaccination With Dickkopf-1 Induces Protective and Therapeutic Antitumor Immunity in Murine Multiple Myeloma. Blood (2012) 119(1):161-9. doi: 10.1182/ blood-2011-07-368472

71. Liu TT, Wu Y, Niu T. Human DKK1 and Human HSP70 Fusion DNA Vaccine Induces an Effective Anti-Tumor Efficacy in Murine Multiple Myeloma. Oncotarget (2018) 9(1):178-91. doi: 10.18632/oncotarget.23352

72. Chaffer CL, Weinberg RA. A Perspective on Cancer Cell Metastasis. Science (80- ) (2011) 331(6024):1559-64. doi: 10.1126/science.1203543
73. Johansson M, Giger FA, Fielding T, Houart C. Dkk1 Controls Cell-Cell Interaction Through Regulation of Non-nuclear $\beta$-Catenin Pools. Dev Cell (2019) 51(6):775-86.e3. doi: 10.1016/j.devcel.2019.10.026

74. Mundy GR. Metastasis to Bone: Causes, Consequences and Therapeutic Opportunities. Nat Rev Cancer (2002) 2:584-93. doi: 10.1038/nrc867

75. Azimi F, Scolyer RA, Rumcheva P, Moncrieff M, Murali R, McCarthy SW, et al. Tumor-Infiltrating Lymphocyte Grade is an Independent Predictor of Sentinel Lymph Node Status and Survival in Patients With Cutaneous Melanoma. J Clin Oncol (2012) 30(21):2678-83. doi: 10.1200/JCO.2011.37.8539

76. Li T, Fu J, Zeng Z, Cohen D, Li J, Chen Q, et al. TIMER2.0 for Analysis of Tumor-Infiltrating Immune Cells. Nucleic Acids Res (2021) 48(W1):W50914. doi: $10.1093 /$ nar/gkaa407

77. Talmadge JE, Gabrilovich DI. History of Myeloid Derived Suppressor Cells (Mdscs) in the Macro- and Micro-Environment of Tumour-Bearing Hosts. Nat Rev Cancer (2013) 13(10):739-52. doi: 10.1038/nrc3581

78. Katoh M, Katoh M. Molecular Genetics and Targeted Therapy of WNTrelated Human Diseases (Review). Int J Mol Med (2017) 40:587-606. doi: 10.3892/ijmm.2017.3071

79. Mazon M, Larouche V, St-Louis M, Schindler D, Carreau M, Carreau M. Elevated Blood Levels of Dickkopf-1 are Associated With Acute Infections. Immun Inflammation Dis (2018) 6(4):428-34. doi: 10.1002/iid3.232

80. Chae W-J, Bothwell ALM. Dickkopf1: An Immunomodulatory Ligand and Wnt Antagonist in Pathological Inflammation. Differentation (2019) 108:33-9. doi: 10.1016/j.diff.2019.05.003

81. Bais AG, Beckmann I, Lindemans J, Ewing PC, Meijer CJLM, Snijders PJF, et al. A Shift to a Peripheral Th2-type Cytokine Pattern During the Carcinogenesis of Cervical Cancer Becomes Manifest in CIN III Lesions. J Clin Pathol (2005) 58(10):1096-100. doi: 10.1136/jcp.2004.025072

82. Kennedy R, Celis E. Multiple Roles for CD4+ T Cells in Anti-Tumor Immune Responses. Immunol Rev (2008) 222(1):129-44. doi: 10.1111/ j.1600-065X.2008.00616.x

83. Janssen EM, Lemmens EE, Wolfe T, Christen U, Von Herrath MG, Schoenberger SP. Cd4+ T Cells are Required for Secondary Expansion and Memory in CD8+ T Lymphocytes. Nature (2003) 421(6925):852-6. doi: 10.1038/nature01441

84. Haabeth OAW, Lorvik KB, Hammarström C, Donaldson IM, Haraldsen G, Bogen B, et al. Inflammation Driven by Tumour-Specific Th1 Cells Protects Against B-cell Cancer. Nat Commun (2011) 2(1):240. doi: 10.1038/ ncomms 1239

85. Lefrançois P, Xie P, Gunn S, Gantchev J, Villarreal AM, Sasseville D, et al. In Silico Analyses of the Tumor Microenvironment Highlight Tumoral Inflammation, a Th2 Cytokine Shift and a Mesenchymal Stem Cell-Like Phenotype in Advanced in Basal Cell Carcinomas. J Cell Commun Signal (2020) 14(2):245-54. doi: 10.1007/s12079-020-00563-6

86. Ziegler A, Heidenreich R, Braumuller H, Wolburg H, Weidemann S, Mocikat R, et al. EpCAM, a Human Tumor-Associated Antigen Promotes Th2 Development and Tumor Immune Evasion. Blood (2009) 113 (15):3494-502. doi: 10.1182/blood-2008-08-175109

87. Sideras K, Braat $\mathrm{H}$, Kwekkeboom J, van Eijck $\mathrm{CH}$, Peppelenbosch MP, Sleijfer S, et al. Role of the Immune System in Pancreatic Cancer Progression and Immune Modulating Treatment Strategies. Cancer Treat Rev (2014) 40 (4):513-22. doi: 10.1016/j.ctrv.2013.11.005

88. Labelle M, Begum S, Hynes RO. Platelets Guide the Formation of Early Metastatic Niches. Proc Natl Acad Sci U S A (2014) 111(30):E3053-61. doi: 10.1073/pnas.1411082111

89. Xu XR, Yousef GM, Ni H. Cancer and Platelet Crosstalk: Opportunities and Challenges of Aspirin and Other Antiplatelet Agents. Blood (2018) 131 (16):1777-89. doi: 10.1182/blood-2017-05-743187

90. D’Amico L, Mahajan S, Capietto AH, Yang Z, Zamani A, Ricci B, et al. Dickkopf-Related Protein 1 (Dkk1) Regulates the Accumulation and Function of Myeloid Derived Suppressor Cells in Cancer. J Exp Med (2016) 213:827-40. doi: 10.1084/jem.20150950

91. Capietto AH, Kim S, Sanford DE, Linehan DC, Hikida M, Kumosaki T, et al. Down-Regulation of Plcy2- $\beta$-Catenin Pathway Promotes Activation and Expansion of Myeloid-Derived Suppressor Cells in Cancer. J Exp Med (2013) 210:2257-71. doi: 10.1084/jem.20130281

92. Reya T, O'Riordan M, Okamura R, Devaney E, Willert K, Nusse R, et al. Wnt Signaling Regulates B Lymphocyte Proliferation Through a LEF-1 
Dependent Mechanism. Immunity (2000) 13:15-24. doi: 10.1016/S10747613(00)00004-2

93. Staal FJT, Luis TC, Tiemessen MM. WNT Signalling in the Immune System: WNT is Spreading its Wings. Nat Rev Immunol (2008) 8:581-93. doi: $10.1038 /$ nri2360

94. Park BM, Kim EJ, Nam HJ, Zhang D, Bae CH, Kang M, et al. Cyclized Oligopeptide Targeting LRP5/6-DKK1 Interaction Reduces the Growth of Tumor Burden in a Multiple Myeloma Mouse Model. Yonsei Med J (2017) 58(3):505-13. doi: 10.3349/ymj.2017.58.3.505

95. Arend R, Castro C, Matulonis U, Hamilton E, Gunderson C, LyBarger K, et al. 76 Patients (PTS) With Recurrent Gynecologic Cancer Whose Tumors Have Activating Wnt Pathway Mutations Respond Better to DKN-01, a DICKKOPF-1 (DKK1) Inhibitor. Int J Gynecol Cancer (2019) 29:A40. doi: 10.1136/ijgc-2019-IGCS.76

96. Arend RC, Castro CM, Matulonis UA, Hamilton E, Gunderson CC, Lybarger KSS, et al. Safety and Efficacy of a DKK1 Inhibitor (DKN-01) as Monotherapy or in Combination With Paclitaxel in Patients With Wnt Activated Recurrent Gynecologic Malignancies. Gynecol Oncol (2019) 154:34. doi: 10.1016/j.ygyno.2019.04.080

97. Onsi DE, Savelle H. Leap Presents Positive Clinical Results for the Combination of DKN-01 Plus Keytruda ${ }^{\circledR}$ and Provides Dkn-01 Program Update | Biospace Vol. 1. Cambridge, Mass., USA: Leap Therapeutics, Inc (2019). Available at: https://www.biospace.com/article/releases/leappresents-positive-clinical-results-for-the-combination-of-dkn-01-pluskeytruda-and-provides-dkn-01-program-update/.

98. Ahn VE, Chu MLH, Choi HJ, Tran D, Abo A, Weis WI. Structural Basis of Wnt Signaling Inhibition by Dickkopf Binding to LRP5/6. Dev Cell (2011) 21(5):862-73. doi: 10.1016/j.devcel.2011.09.003

99. Wall JA, Klempner SJ, Arend RC. The anti-DKK1 Antibody DKN-01 as an Immunomodulatory Combination Partner for the Treatment of Cancer. Expert Opin Investig Drugs (2020) 29(0):639-44. doi: 10.1080/ 13543784.2020.1769065

100. Brott BK, Sokol SY. Regulation of Wnt/LRP Signaling by Distinct Domains of Dickkopf Proteins. Mol Cell Biol (2002) 22(17):6100-10. doi: 10.1128/ MCB.22.17.6100-6110.2002

101. Korol O, Gupta RW, Mercola M. A Novel Activity of the Dickkopf-1 Amino Terminal Domain Promotes Axial and Heart Development Independently of
Canonical Wnt Inhibition. Dev Biol (2008) 324:131-8. doi: 10.1016/ j.ydbio.2008.09.012

102. Haniu M, Horan T, Spahr C, Hui J, Fan W, Chen C, et al. Human Dickkopf-1 (huDKK1) Protein: Characterization of Glycosylation and Determination of Disulfide Linkages in the Two Cysteine-Rich Domains. Protein Sci (2011) 20 (11):1802-13. doi: 10.1002/pro.705

103. Steentoft C, Vakhrushev SY, Joshi HJ, Kong Y, Vester-Christensen MB, Schjoldager KTBG, et al. Precision Mapping of the Human O-GalNAc Glycoproteome Through SimpleCell Technology. EMBO J (2013) 32 (10):1478-88. doi: 10.1038/emboj.2013.79

104. Kukuruzinska MA, Lennon K. Protein N-glycosylation: Molecular Genetics and Functional Significance. Crit Rev Oral Biol Med (1998) 9:415-48. doi: $10.1177 / 10454411980090040301$

105. Ghouzam Y, Postic G, De Brevern AG, Gelly JC. Improving Protein Fold Recognition With Hybrid Profiles Combining Sequence and Structure Evolution. Bioinformatics (2015) 31(23):3782-9. doi: 10.1093/ bioinformatics/btv462

106. Ghouzam Y, Postic G, Guerin PE, De Brevern AG, Gelly JC. Orion: A Web Server for Protein Fold Recognition and Structure Prediction Using Evolutionary Hybrid Profiles. Sci Rep (2016) 6:28268. doi: 10.1038/srep28268

107. Yang M, Haas M, Heath H, Schurpf-huber F, Kagey M, Newman W, et al. Antibody Targeting of WNT Signaling Modulator Dickkopf1 ( DKK1) Enhances Innate Anti-Tumor Immunity and Complements anti-PD-1 and Paclitaxel Therapy (2018). Available at: https://fc949ce6-fa24-49e6-bbfd-6f920c9d5cba. filesusr.com/ugd/c343d0_db1fb5bb448a4f98a90ea066b106eef0.pdf.

Conflict of Interest: The authors declare that the research was conducted in the absence of any commercial or financial relationships that could be construed as a potential conflict of interest.

Copyright (c) 2021 Chu, Chen, Wang, Zhang, Tan, Liu, Zhang, Lu, Yu and Zhang. This is an open-access article distributed under the terms of the Creative Commons Attribution License (CC BY). The use, distribution or reproduction in other forums is permitted, provided the original author(s) and the copyright owner $(s)$ are credited and that the original publication in this journal is cited, in accordance with accepted academic practice. No use, distribution or reproduction is permitted which does not comply with these terms. 